\title{
Introduction: Experimental, Minimalist, Postminimalist? Origins, Definitions, Communities
}

\author{
Kyle Gann, Keith Potter and Pwyll ap Siôn
}

Consider, to begin with, the summer of 1974. In that summer, the pre-eminent

German record label Deutsche Grammophon released a three-record set of music by

Steve Reich, a composer of whom, at that time, most classical-music record-store browsers had probably not yet heard. Prior to that moment, Deutsche Grammophon, along with issuing the usual sets of the Beethoven, Brahms and Sibelius symphonies, had championed the ultra-complex music of Karlheinz Stockhausen, Bruno Maderna, Hans Werner Henze and other controversial luminaries of the European avant-garde. The impact of that company lending its prestigious imprimatur to an unknown American composer writing in a brand new style - a tonal style, yet, in the great age of atonality - can hardly be overstated. In that summer, minimalist music suddenly burst, from the lofts of Manhattan and the electronic studios of San Francisco, into public consciousness. And that record set took off. In the 1970s many considered it a holy icon.

We can argue, and will in this volume, about the chronology of minimalism's creative origin, but no one can really dispute that the summer of 1974 marked a new 
stage in the style's public and institutional profile. By most accounts, minimalism was an incipient product of the late 1950s or early 1960s. Some would date the style from La Monte Young's extremely slow Trio for Strings of 1958; others from Terry Riley's perhaps more crowd-pleasing In $C$ of 1964; still others might argue for predecessors in the early-1950s experiments of Belgian composer Karel Goeyvaerts, and even in the 1940s music of John Cage. The style had been percolating at La Monte Young's Manhattan loft, at the San Francisco Tape Music Center, among faculty at CalArts, at the ONCE festival in Ann Arbor and elsewhere for years before the wider world became aware of it. Certainly, by the time Michael Nyman suggested the term minimal music in 1968, a large group of composers, mostly but not exclusively American, had made drones, repetitive figures, strict process and gradual change a matter of considerable collective excitement. ${ }^{1}$

How large a group? The names of many of the original minimalists are so unknown to the general public that only four have become standard enough to mention: La Monte Young, Terry Riley, Steve Reich and Philip Glass. Yet prior to the widespread fame of these four, we have to cede some measure of precedence to a host of others: Barbara Benary, Harold Budd, John Cale, Rhys Chatham, Tony Conrad, Philip Corner, Arnold Dreyblatt, Julius Eastman, Jon Gibson, Terry Jennings, Dennis Johnson, Tom Johnson, Angus MacLise, Richard Maxfield, Meredith Monk, Phill Niblock, Pauline Oliveros, Charlemagne Palestine. These are the Americans, many of whom were in close contact and mutually involved in performances of each other's works. To these we can add, without passing beyond the mid-to-late 1970s, Gavin Bryars, Christopher Hobbs, Michael Nyman, Hugh Shrapnel and Howard Skempton

\footnotetext{
${ }^{1}$ Michael Nyman, 'Minimal Music', The Spectator, 221/7320 (October 1968): pp. 518-19.
} 
in Great Britain; Karel Goeyvaerts in Belgium; in France, Eliane Radigue; Per Nørgård in Denmark; the Hungarians Zoltán Jeney and László Sáry; and arguably many others.

There is some value, then, in thinking of minimalism as a large, diverse, unruly repertoire of which the concertgoing and record-listening public became aware of only the tip of the iceberg. Those whose idea of minimalism is embodied by Reich and Glass think of it as a pretty, somewhat ambient body of music using repetitive patterns and a simple tonality. The minimalism of the early 1960s, however, was often deafeningly loud, gritty, unconventionally tuned and extended to lengths that challenged one's attention span. At first slowly developing in the cocoon of an underground, minimalism made a big jump to the larger world in 1974, and another in 1976, when Glass's Einstein on the Beach and Reich's Music for 18 Musicians were premiered. Then, in the early 1980s, minimalism shed its outsider status and went on to re-energize the classical music world itself.

Subsequent to the success of Einstein, for instance, Glass began to receive commissions from famous European opera houses. Music for 18 Musicians became so popular that Reich was asked to write orchestral works, such as The Desert Music (1983) and The Four Sections (1987). In the late 1970s John Adams burst onto the public sphere as the 'fifth minimalist' with Shaker Loops and Phrygian Gates (both 1978); today he may well be the most widely-performed American composer, and the most widely recognized aside from Reich and Glass. Michael Nyman started out writing rather experimental minimalist works and, initially through his connection with the filmmaker Peter Greenaway, became well-known for film scores, particularly his later soundtrack for the movie The Piano (1993). In Holland, Louis Andriessen moved in a minimalist direction, composing many celebrated orchestral and operatic 
works, De Staat (The Republic) (1972-76) and De Materie (Matter) (1984-88)

among the best known. The Estonian composer Arvo Pärt, evolving his own brand of reductionist music after experiments with 12-tone style and aleatory techniques, was introduced to the West in the early 1980s by the record label ECM and became an overnight sensation. His Fratres (1977), rewritten for several different instrumentations, is among the most widely recognized of modern works.

In short, evolving from its hippie, low-tech beginnings a quarter-century earlier, minimalism became far and away the most well-known and commercially successful new style of what we still call 'classical music' in the late twentieth century. Other classical styles continue - one might mention the New Romanticism (which has a certain overlap with minimalism) and the ongoing dissonant abstraction of what's come to be termed High Modernism - but the composers who command a large following both within and outside the orchestral establishment are pretty much those known, or formerly known, as minimalists. Adams, Andriessen, Bryars, Glass, Nyman, Pärt, Reich and Riley - these are international stars of contemporary music, purported minimalists all. Though the music remained controversial in musical academia (as much for its popularity as for its overestimated simplicity), no other body of notated music had won over so broad a public following since the end of the Romantic Era. Minimalism is the great success story of twentieth-century classical music: the 'wacko' avant-garde movement that went 'legit'.

With universal recognition, inevitably, come vagueness and caricature: today, in the blogosphere and elsewhere, Gregorian chant, Erik Satie, Ravel's Bolero, the opening of Wagner's Das Rheingold and gamelan music have all been described as minimalist, as the term expands in ever-widening circles to be applied to interior decorating, website design, haute cuisine and so on. Meanwhile, the more 'difficult', 
experimental brand of minimalism continues to be created today (by Tom Johnson, Niblock, Radigue and others), so that a cult continues for a 'hard-core' style that would deliberately try the patience of the average concertgoer.

In musicology, on the other hand, minimalism is sometimes spoken of as a historical style that came to an end in the late 1970s. In addition, there are by this writing a couple of subsequent generations of composers who started out with minimalist proclivities and evolved a music so patently descended from minimalism, yet quite different from it, that some have termed it postminimalist; where will we draw the line? Based on what criteria? In short, the word minimalism has acquired connotations so diffuse as to be meaningless, others so narrow as to be known only to specialists, and still others so vague that we've only recently started arguing about them.

\section{Some Attempts to Define Minimalism}

The musicological problem, then, before we can even approach the subject with any lucidity, is: how, for the purposes of an explanatory volume, should we define minimalism? Minimalist composers, most of whom have disavowed the term (Tom Johnson emphatically excepted) are of little help. The stereotype based in the world's general knowledge of the early music of Philip Glass and Steve Reich and Terry Riley's In $C$, is that minimalism is repetitive music, in which melodic or rhythmic 
figures are incessantly repeated, often with some gradual change taking place, like lengthening or phase-shifting. Yet this cursory definition is, historically speaking, woefully incomplete. It omits the drone improvisations of La Monte Young's The Theatre of Eternal Music (which must be dealt with in any introduction to the style), or the slowly glissandoing drones of Phill Niblock, or the lengthy piano or organ extravaganzas of Charlemagne Palestine, or the atmospheric vignettes of Harold Budd. Given the continuing underground interest in The Theatre of Eternal Music (and its rock offshoot The Velvet Underground), and the growing familiarity of Niblock, it is likely (and welcome) that the current public image of minimalism will become more nuanced, more informed by scholarly contributions. We hope with this volume to provide a push in that direction.

Ultimately, the meaning of the term must be a compromise between the facts of the original scene, which remains largely unknown to those without a scholarly interest in the field, and the public's awareness of this style. That the word already means something is undeniable, and we would contend against such public stereotypes in vain; that it should be allowed to mean anything is not in the best interests of scholarship.

In fact, to one who knows the relevant literature it seems clear that no single technical criterion for minimalist music will suffice. Simply to look at the activities of the original minimalists, as they were working closely together in the 1960 s in a fertile crossbreeding of ideas, is to realize that there was a general interest in a number of techniques, related but not easily reduced to a single principle. The similarities among minimalist works are not universal, but rather what Ludwig Wittgenstein would have characterized as family similarities, in such a way that a group of associated features exist, any of which may be found in some examples but 
not in others. We will list the most obvious of these here, while emphasizing that no one of them can be found in all works we might want to term minimalist.

\section{Harmonic Stasis}

Starting with Young's Composition 1960 No. 7, if not indeed earlier with Dennis Johnson's November (1959), the minimalists felt a fascination with reduction to a small number of pitches: either a single chord, as in some of Young's sine-tone installations; a few pitches, as in Reich's Piano Phase (1967); a few chords, as in Reich's Octet (1979); or a single scale, as in Glass's Music in Fifths (1969). Most typically the pitch set or harmonies involved imply a conventional diatonic scale or mode, though there are important exceptions, such as Niblock's microtonal music and James Tenney's Chromatic Canon (1980), which applies a minimalist process to a 12 note row. It is natural to perceive this reductionism as a reaction to the massive serialist and aleatory works of the 1950s and 1960s, which seemed to include just about everything.

\section{Repetition}

A stuck-in-the-groove feeling of repeated melodic or rhythmic figures is the most stereotypical aspect of minimalist music as most listeners think of it, though it should be noted that prolonged exact repetition without some gradual or terraced transformation is extremely rare. With a nod to Erik Satie's Vexations, written in the 1890s but first staged by John Cage in 1963, such repetition enters the history of minimalism with Dennis Johnson's piano piece November, then more noticeably in Riley's tape pieces from 1963, Mescalin Mix and The Gift. The popularity of early 
works by Glass and Reich made repetition seem central, but there was already, and has been since, a minimalist repertoire not concerned with it.

\section{Drones}

It would seem that there is no easier nor clearer way to make minimalist music than to take a sonority and sustain it. The importance of drones for the musics of Niblock, Palestine and The Theatre of Eternal Music has been mentioned, and they play a role in the early musics of Glass and Reich as well. 'Pulse-based music' versus 'dronebased music' has sometimes proved a convenient way to sort out minimalist music into two types, but sometimes the distinction simply depends on instrumentation: since the organ can sustain and the piano cannot, Palestine tended to use drones on one and repetitions on the other.

\section{Gradual Process}

The possibility of gradual process, as constituting a new and fascinating perceptual challenge for listeners, was basic to early minimalism; in fact, for a while in the 1960s and 1970s 'Process Music' was a common and overlapping term, inclusive of composers who might not be considered minimalist (Alvin Lucier, David Behrman and, in certain works, Tenney being strong examples), while excluding minimalist composers whose music was less linear (such as Budd). Among the types of process commonly used were: 
- Additive process, in which, most commonly and especially associated with Glass, a work would start with a basic repeated pattern and add or subtract notes to lengthen or shorten it, often in a pattern such as $1,1+2,1+2+3$, $1+2+3+4$ and so on (Music in Fifths, Music in Similar Motion (1969), Einstein on the Beach, also Frederic Rzewski's Les Moutons de Panurge (1969), Coming Together (1971) and Attica (1972)). Alternatively, the repeating rhythmic unit could maintain a constant duration and the number of notes within it be gradually increased (as in Reich's seminal Drumming (1970-71)); or an existing pattern could be slowed down and sped up (Reich's Music for Mallet Instruments, Voices and Organ (1973) and Music for 18 Musicians).

- Phase-shifting, in which two identical phrases would be played at the same time but at slightly different tempos so as to go out of phase with each other. This technique is almost entirely identified with Reich's early works, such as It’s Gonna Rain (1965), Come Out (1966), Piano Phase and Drumming, though as a structural model it survived as an important archetype in postminimalist music as well (e.g. William Duckworth's Time Curve Preludes (1979), John Luther Adams's Dream in White on White (1992)).

- Permutational process, in which a melodic progression would gradually change via some systematic transformation that precluded exact repetition (Jon Gibson's Melody IV (1975), Tom Johnson's Nine Bells (1979) and the early works of Barbara Benary).

Steady Beat 
One could say that in general minimalism was associated with a motoric quaver-note beat, although given the tendency of composers such as Young and Niblock to rely on drones with no beat at all, it might be more accurate to say that minimalism was characterized by a lack of rhythmic differentiation.

\section{Static Instrumentation}

Due to the logistics of early minimalist performance practice, the style originated in small, composer-led ensembles such as The Theatre of Eternal Music, Steve Reich and Musicians, and the Philip Glass Ensemble, which were all founded on a rather ritualistic concept of everyone playing all the time, often with the instrumentation left somewhat open. Minimalist ensembles hardly ever display the classical European paradigm of the painter's palette in which each instrument adds its dash of colour where needed. Equally, one could say that this aspect began to change once minimalism moved into the orchestral sphere, so that it may have been determined more by the innovative and evolving economics of minimalist performance than by any permanent aesthetic goal.

\section{Metamusic}

For a while in the 1970s it seemed that Reich's chief preoccupation was the unintended acoustic details that arose (or were perceived) as a side-effect of strictly carried-out processes. These included soft melodies created by the overtones of played notes, which Reich referred to as 'metamusic' and even reinforced with notated instrumental melodies in such works as his Octet. One could say that the 
overtone phenomena buzzing above the slowly glissandoing drones of Niblock's music, and even the changing overtone patterns heard as you walk through a Young sine-tone installation, constitute metamusic as well.

\section{Pure Tuning}

It's noteworthy that minimalism started, in the musics of Young, Tony Conrad, and The Theatre of Eternal Music, as a slowed-down exploration of pure frequency ratios, resonant intervals outside the 12-pitch piano scale; Niblock's music and much of Riley's continue to use this feature as well. Once common in what we could call hardcore minimalism, this feature has fallen by the wayside in better-known parts of the repertoire, although Adams reintroduced pure harmonics in his orchestral work The Dharma at Big Sur (2003).

\section{Audible Structure}

One thing shared by many classical minimalist works (notably Drumming, In $C$, Attica, Composition 1960 No. 7 and Einstein on the Beach) was that their structure was on the surface and easily audible, that you could tell just from listening, often just from the first audition, what the overall process was. The singers' counting of beats in Einstein was iconic. Reich's early writings, in particular, emphasized that part of minimalism's early mystique was to have no secrets, to hold the music's structure right in the audience's face and have that be listened to. 


\section{Time and the Perception of Minimalist Music}

All of these features are associated with certain works that we think of as classically minimalist, but there may be no works, or at least very few, that contain all of them. (There are pieces, such as Philip Glass's Music with Changing Parts (1970) and Frederic Rzewski's Coming Together, that contain both drones and a steady quavernote pulse, as well as gradual transformation, and so on.) These technical features are helpful in pinning down the repertoire we want to discuss, because we want to maintain a central focus on the historical facts of minimalism. The reality remains that in the 1960s and 1970s a certain group of composers took up a common interest in the auditory and psychological effects of certain static or slowed-down phenomena. Wherever we go with our general explanation and definition of minimalism, we do not want to lose sight of the historical reason that there was something to define in the first place.

Intuitively, though, one feels that all these techniques tended toward some similar state. First of all, the term: minimalism. Something seems minimal - or less than we expected. Less compared to what? To what we're accustomed to hearing. We are used to hearing classical music, modernist music, jazz, pop, and when we hear minimalist music, we get less than we expect. Fewer pitches, less contrast, fewer events, less change. Often, especially in the early history, we find longer duration as well, which adds emphasis to the austerity of the materials. Something seems to be 
missing. On one hand the music has less variety than our attention spans are attuned to; saying it another way, the music seems to go on for too long, in some sense, for the amount of events that happen within it.

Events happen in time, and, in fact, articulate time. Events bring to our consciousness the perception that time is passing by. Our relation to events is how we judge that time is passing. As we listen to conventional classical music, we hear a succession of different themes, marked off by cadences that bring a section to a close, or deceptive cadences that contradict our expectation that the music is about to end. In jazz, we hear a succession of solos, within a frame consisting of the 'head', which is played at the beginning and end of a tune. In pop music, we hear verses and choruses that tell us where we are in the music. Anyone superficially familiar with such styles gains an instinct for the periodicity with which the music 'breathes'. Minimalism, with its contrast-free continuity of drones, repetitions, processes and so on, tends not to breathe. There are often few clues for the listener as to where we are in the piece. The sense of time is different than in most music we hear in the West, though we may find echoes in world traditions such as Indonesian gamelan, Japanese gagaku and Tibetan chanting.

Why do minimalism's fans see this lack as a positive? We can answer from a psychological standpoint with a quotation from the psychoanalyst Peter Hartocollis:

[W]hen one is not concerned with time, one is likely to see oneself as happy - timelessness or the sense of eternity being identified with the condition of ecstasy ... The essence of [this] mystical experience ... is in its complete freedom from any sensual or aggressive wish, the freedom from internal pressure and perception of the surrounding world as devoid of any exciting elements, threatening or promising possibilities. The concept of time as a dimension 
of reality that defines self from object ('succession of events') is canceled and replaced by a sense of unity. ${ }^{2}$

We all know that some of our happiest moments are when time seems to disappear. When listening to minimalist music, we begin, out of habit (unless minimalism is our accustomed repertoire), to listen for events that cue us in to what's going on in the music, how long the piece is going to last, what scale its sections are arranged in and so forth. Minimalist music quite often denies us or delays these cues, irritating some listeners and giving others a freeing sensation that the passage of time, the articulated structure of the piece, need not be kept track of. Some of us feel happier.

Detailing the actual physiology would take us far out of our sphere, but some have related this sense of timelessness to differences of perception that have often in the past been generally assigned to the left and right hemispheres of the brain. ${ }^{3}$ What has been called left-brain perception keeps track of time, creates hierarchies of events and attaches verbal signifiers to phenomena. What has been called right-brain perception is more holistic, less defining and more accurately registers nuances and contours that words would be inadequate to describe. Current science discredits the idea that different brain functions are actually located in specific areas of the brain. Modern theories now revolve around neural networks that link up different areas of the brain to give different kinds of response. But the essential distinction being made

\footnotetext{
${ }^{2}$ Peter Hartocollis, 'On the Experience of Time and its Dynamic, with Special Reference to the Affects', Journal of the American Psychoanalytic Association, 24 (1976): pp. 368-70; quoted in Jonathan Kramer, The Time of Music (New York, 1988), p. 377.

${ }^{3}$ Particularly the late Jonathan Kramer, in his masterful study The Time of Music.
} 
here, between two kinds of appreciation of time and the correspondingly different categories of reaction to music that flow from this, still stands.

Most musicians are familiar with the state of mind in which they've been performing really well, 'lost' (as we put it) in the emotion and physicality of their playing, and they've lost all sense of time. We call 'lost' that disappearance into a nonverbal world of feeling and atmosphere, in which before and after cease to be noticed. Psychologists have identified this state as immersion in a right-brain kind of experience. To some extent, minimalist music made more available to the listener aspects of right-brain experience that had always been the purview of the performer.

If this benefit sounds so obvious, why hadn't our music done so before? One answer is to look at the social functions that music had historically fulfilled in the West. Concert listening, whether classical or jazz, mostly took place in front of audiences sitting in chairs and looking at the stage. In order to gain and retain their full attention, the emotive and atmospheric aspect of the music was accompanied by a kind of structural narrative of tunes and harmonic resolutions, so that the keepingtime aspect of the listeners' minds was also satisfied. Early minimalist music began to be performed in a different kind of setting, in lofts and at all-night concerts, in which audience members were freer to move around, lie down and even (let's admit it) engage in drug or alcohol use at some level. The social situation began to resemble more closely that of attendance at Asian or African musical rituals.

Meanwhile, the synchronicity that music came to be listened to more often on recordings than in live performance undoubtedly helped minimalism catch on with a large audience. (It is no coincidence that we began this essay by citing a recording, not a performance.) To register all the mercurial wit in a Haydn string quartet, or the 
ingenuity of a series of Coltrane solos, requires a detailed kind of attention facilitated by physical presence; to 'chill out' to Reich's Drumming is a more ambient, globalized kind of listening nearly as available on recording as it is while lounging on pillows in the performance space. That is not to deny that a minimalist process can engagingly absorb one's full attention, but often in a temporally unarticulated way. It seems almost too obvious to mention that minimalism has thrived partly because it so aptly fits the electronic means of musical transmission ubiquitous in our digital world. For younger listeners, even their concert expectations are strongly conditioned by prior experience with recordings.

For instance, let's take one of the classics of minimalism, Reich's electronic piece Come Out - which is itself nothing but a recording. Consciously one knows, or will quickly realize, that the phrase 'Come out to show them' is going to be played on two different speakers, starting at once but ever-so-gradually going out of phase. From a left-brain point of view, there's hardly any reason to listen to it, because you know in advance what's going to happen. There will be no events, no surprises. But of course, what happens viscerally is very surprising indeed. Gradually we start to hear the phrase 'Come out to show them' as a melody, and an awareness of the piece as being in (or on) a certain key (that of $\mathrm{C}$ minor). The phasing process tonalizes the spoken phrase, abstracting pitches and contours from its verbal meaning and changing our perception of the phrase in ways that were impossible to anticipate before Reich discovered them. The particular pleasure here is difficult to verbalize: evidence that the right brain is involved. At some point we can hardly believe that the transformations all stem from the simple phrase we heard in unison at the beginning. Our analytical understanding can hardly account for our sensuous fascination. 
Another clear example is Philip Glass's Einstein on the Beach. In some scenes from the opera, repeated patterns change in a linear way that are easy to chart out in the score. But in the ongoing rush of repetitions, successive repeated patterns often start with the same notes, so that one can't determine while the music is playing when the patterns change, but only notice it in hindsight, often with a kind of surprise. A similar experience may be found while listening to Arvo Pärt's Cantus in Memory of Benjamin Britten (1977) - we sense but cannot aurally define or follow the large-scale tempo canons formed by those lines that move at different rates of speed. A more forceful European example is the series of 144 identical fortissimo chords that open Louis Andriessen's De Materie. In the first moments the educated brain can analyze that chord, confirm that all the repetitions are identical and measure to some extent the fact that they are speeding up. But after a few seconds our conscious mind has done everything it can, except count - and who wants to count chords? So the understanding bows out, and we are left to the mercy of the temporally indefinable repetition. Even though in a sense we know exactly what is going on, one can only experience the music during that long moment - quite pleasurably, in our view - as an irrational, unexplainable phenomenon.

It would not do to overstate this point. For thousands of minimalism fans, the music's great virtue is that one submits to it, that it seduces us into a kind of sonic meditation and colours that meditation as we revel in a welcome, relaxing, thoughtallaying sense of timelessness. To reduce our definition of the movement to this feeling, however, would exclude much of the music covered in this volume. To mention one of the most dramatic examples, when John Adams took those Glassian/Reichian repetitions into the opera house and made them the accompaniment to the musings of Richard Nixon and Henry Kissinger in Nixon in China (1987), the 
style moved back into, and infiltrated, a more traditional performance paradigm.

(Alternatively: must we therefore call this postminimalism?) What we call

minimalism is by now no unitary phenomenon, but a complex web of musical tendencies that has changed shape and meaning as it has moved into a greater variety of performance situations.

\section{Minimalist Music and Scholarship}

Because so many aspects of early minimalism seemed impervious to analysis, and because analysis is often the life-blood of scholarly inquiry, musicologists initially had a generally hostile attitude toward the movement, and in many pockets continue to do so today. One of the first books on the subject, K. Robert Schwarz's Minimalists, opens with the words, 'Many do not consider minimalism to be an entirely respectable field of academic pursuit' ${ }^{4}$ - and this as recently as 1996 . For decades scholarly writing on the subject seemed virtually verboten. Perhaps the first book to recognize minimalism as a musical movement was Michael Nyman's groundbreaking Experimental Music: Cage and beyond, first published in 1974. Nyman grouped Young, Riley, Reich and Glass together, but also provided a rare score example from Terry Jennings, and linked the Americans with British composers

\footnotetext{
${ }^{4}$ K. Robert Schwarz, Minimalists (London, 1996), p. 6.
} 
who were producing similar work, such as Gavin Bryars, Christopher Hobbs, Hugh Shrapnel and Howard Skempton. The same year (and the same year as the aforementioned Deutsche Grammophon three-record set), Universal published a little book of Reich's essays, Writings About Music, which set out the theories and intentions of one of minimalism's primary practitioners. ${ }^{5}$

Appearing originally in Flemish in 1980, then translated into English in 1983, the book American Minimal Music by Wim Mertens (himself a composer of minimalist proclivities) further codified and confirmed the Young/Riley/Reich/Glass grouping. ${ }^{6}$ Mertens not only offered a number of helpful score samples for a readership who had been starved of them, but contextualized the movement in terms of ideas associated with philosophers such as Theodor Adorno and Jean-Francois Lyotard, and modernist composers such as Stockhausen. Tom Johnson had written frequent journalistic articles about minimalism in the New York newspaper The Village Voice from 1972 to 1982; in 1989 a collection of his writings appeared called The Voice of New Music, ${ }^{7}$ which reprinted clinically phenomenological descriptions of the music as it had appeared in its original performances. Edward Strickland published a book in 1993, Minimalism: origins, ${ }^{8}$ that traced the concept from the world of visual art into music, along with an admirably detailed account drawn from

\footnotetext{
${ }^{5}$ Steve Reich, Writings about Music, Kaspar Koenig (ed.) (Halifax, Canada/New York, 1974).

${ }^{6}$ Wim Mertens, American Minimal Music: La Monte Young, Terry Riley, Steve Reich, Philip Glass, trans. J. Hautekiet (London, 1983).

${ }^{7}$ Tom Johnson, The Voice of New Music, 1972-1982: a collection of articles originally published in the Village Voice (Eindhoven, 1989).

${ }^{8}$ Edward Strickland, Minimalism: origins (Bloomington and Indianapolis, 1993).
} 
interviews with the participants of the exact history of early minimalist activities and their influence.

The late K. Robert Schwarz's Minimalists (1996) was a kind of watershed in the reception history of the movement: the first widely available introduction, explaining minimalism to a broad audience and significantly expanding the (post)minimalist canon to include Adams, Louis Andriessen, Meredith Monk, Michael Nyman and Arvo Pärt. This opened the floodgates, and proved to the publishing world that the music was here to stay and that people wanted to read about it. Kyle Gann's American Music in the Twentieth Century included a chapter on minimalism that mentioned many lesser-known figures $;{ }^{9}$ more significant may be the fact that that chapter appeared in the very centre of the book, with two generations of postminimalists treated in subsequent pages. Finally, in 2000 came the first scholarly examination of minimalist music's primary sources, Keith Potter's Four Musical Minimalists, ${ }^{10}$ which focused once again on the Young/Riley/Reich/Glass tetrad, covering the movement in thorough musicological detail up until 1976.

Important books and articles on the subject followed during the first decade of the new century, and the number of $\mathrm{PhD}$ theses in this area have become too innumerable to list. Robert Fink’s Repeating Ourselves: American minimal music as cultural practice $^{11}$ (2005) might be said to have initiated the revisionist, interpretative, even postmodernist phase of writing and thinking about minimalism, tying it in with

\footnotetext{
${ }^{9}$ Kyle Gann, American Music in the Twentieth Century (New York, 1997).

${ }^{10}$ Keith Potter, Four Musical Minimalists: La Monte Young, Terry Riley, Steve Reich, Philip Glass (Cambridge, 2000).

${ }^{11}$ Robert Fink, Repeating Ourselves: American minimal music as cultural practice (Berkeley, 2005).
} 
developments in popular music and hearing it through the wider perspective of mass culture. Today, with books available on Young by Jeremy Grimshaw, ${ }^{12}$ Nixon in China by Timothy A. Johnson, ${ }^{13}$ Nyman by Pwyll ap Siôn, ${ }^{14}$ Tony Conrad by Branden W. Joseph, ${ }^{15}$ and a thorough account of the style in Richard Taruskin's The Oxford History of Western Music, ${ }^{16}$ any idea that minimalism is not respectable enough to merit scholarly scrutiny has been consigned to historical musicology's dustbin. In recognition of its widespread popularity, minimalism is arguably the repertoire of late twentieth-century classical music that is most often written about today.

\section{A Summary of the Present Volume's Chapters}

The main aim of this volume, as with previous Ashgate Research Companions, has therefore been threefold. First, it is designed to provide the reader with a

\footnotetext{
12 Jeremy Grimshaw, Draw a Straight Line and Follow It: the music and mysticism of La Monte Young (Oxford, 2011).

13 Timothy A. Johnson, John Adams’s Nixon in China: musical analysis, historical and political perspectives (Farnham, 2011)

${ }^{14}$ Pwyll ap Siôn, The Music of Michael Nyman: texts, contexts and intertexts (Aldershot, 2007).

${ }^{15}$ Branden W. Joseph, Beyond the Dream Syndicate: Tony Conrad and the arts after Cage (Brooklyn, 2008).

${ }^{16}$ Richard Taruskin, The Oxford History of Western Music (Oxford, 2005).
} 
comprehensive overview of past and present research in minimalist and postminimalist music. Secondly, it tries to give an account of the broad range of musicological practices now being applied by a large community of academics in this area. Finally, it offers a glimpse of new and interesting directions that future scholarship may take.

With this in mind, the Ashgate Research Companion to Minimalist and Postminimalist Music is divided into six parts. Part I addresses minimalism's impact from a historical and regional perspective. Keith Potter maps its early topography by looking afresh at how the movement emerged, and questions the extent to which the 'pulse-pattern' works of the late 1960s by such composers as Steve Reich and Philip Glass can be seen as a natural outcome of their cultural context. Can this repertoire properly be regarded as the foundation of the musical aesthetics, styles and techniques commonly regarded as 'minimalist' today? What alternative interpretations of the history of early musical minimalism are available, and to what extent should these be challenging more familiar and accepted notions of how, where and why this still highly influential musical phenomenon arose?

'Mapping Early Minimalism' is followed by a chapter that sets out to define the characteristics and meanings of a movement that developed out of minimalism now known as postminimalism. This broad repertoire of music is based on the diatonic patterns and steady pulse of minimalism, but has eschewed its linear processes and extended lengths. Kyle Gann's overview is both historical and regional in that it identifies similar compositional devices in a large number of works by predominantly North American composers while simultaneously developing a stylistic and analytical terminology that will be helpful in assisting future scholarship in this area. 
Maarten Beirens's account shifts the regional focus to Europe in general and to the Low Countries in particular, arguing that European minimalists were active in a context that was far more determined by Western musical traditions and by the ideology of musical progress than in the USA. As a result, many examples of European minimalism have been decidedly referential in approach - towards historical examples, stylistic elements and specific music from the past. Drawing upon examples from the music of Karel Goeyvaerts and Louis Andriessen, Beirens addresses the way in which European minimalism often engages dialectically with minimalist techniques and its aesthetic in order to place it both within the European tradition and in relation to American minimalism.

Part 1 concludes with Virginia Anderson's survey of minimalist music in Britain. She focuses on the importance of systems and related approaches, from the austere, sparse minimalism of Christopher Hobbs and Howard Skempton in the late 1960 s to a return to non-narrative approaches in the 1980 s, as digital electronic instruments and software appeared. Anderson's chapter provides a valuable link between minimalist music during its experimental heyday in the 1960s and minimalism in Britain during the 1970s, and its development in the later works of English composers such as Gavin Bryars and Michael Nyman, whose musical language still retains much of the movement's experimental ethic.

Part II assesses minimalism's identity beyond purely musical concerns by looking at its relationship with theatre. Dean Suzuki's chapter on minimalism in the time-based arts sets off from the premise that many minimalist composers belonged to a more extended community that included visual artists, dancers, directors and producers who shared common aesthetic beliefs and aims. Many of these artists collaborated with one another - Young provided a score for Andy Warhol's film 
Empire, for example - while some moved creatively across a number of disciplines, such as Tony Conrad, Laura Dean, Richard Serra and Michael Snow.

Jelena Novak's chapter traces minimalism's journey from abstraction towards representation in a new form of contemporary opera that coincided with the emergence of minimalism, which she defines as postopera. She sees Glass and Robert Wilson's landmark multimedia opera Einstein on the Beach as symptomatic of this new form in its shift from modernity to postmodernity. This shift is also seen in composers' 'recycling' of other musical languages or engaging with extra-musical phenomena in postoperatic works, especially in Andriessen's music.

The underlying focus in Jeremy Peyton Jones's chapter is on the audience's perception of repetition and its effects on the listener/viewer. 'Accommodating the threat of the machine' examines the physical aspects of the performance of repetitive music, making connections with physical repetition in dance and theatre, considering the effects and meanings inherent in the use of repetition both as a structural element and articulating those moments where it moves beyond structure to incorporate other aspects.

Following on from Part II, minimalism's relationship with other media is the subject of the four chapters contained in Part III. Richard Glover's chapter identifies and explores the various uses of technology since the rise of minimalism in the 1960s - how technology helped shape the notion of similarity and repetition in minimalist composers' approaches. Different approaches often took composers along markedly different courses, as seen in the experiences of Young and Reich. Young's instrumental work with The Theatre of Eternal Music led to the electronicallygenerated sine tones of the Dream House, while Reich's experiences with tape loops 
brought him back to acoustic instruments and live performance. Composers working on the intersection between experimental tape music and minimalism are also considered, such as James Tenney's early process-based work with tape and computer or Alvin Lucier's pioneering work with technology and live performance. The music of Phill Niblock, Charlemagne Palestine and Eliane Radigue is covered in some detail, while trends in more recent minimalist electronic music provide a focal point for a discussion on the capabilities of digital processing in the music of Richard Chartier, Ryoji Ikeda and Mark Fell and Mat Steel's group snd.

A similar journey from avant-garde to mainstream popular culture is traced in the following chapter by Rebecca Eaton, this time in relation to minimalist music's use in film soundtracks. Mainly an avant-garde phenomenon during the 1960s and early 1970s, minimalist music's film status was reflected in short, experimental, arthouse productions and documentaries. However, following Glass's success with Koyaanisqatsi in 1982, minimalist music moved closer to the cinematic mainstream and by the 1990s could be heard in horror and science-fiction films. Its forms and techniques were also adopted by composers not known for writing in this style, such as John Williams and James Horner.

Minimalism's appearance in blockbuster films is perhaps one of its most remarkable stories, given how dramatically it differs from the dominant Romantic style of the classical Hollywood film score. On the other hand, such uses can be understood more broadly, for example in terms of repetitive minimalism's evocation of industrial modernity and mass media. As shown in Robert Fink's chapter 'Going with the flow: minimalism as cultural practice in the USA since 1945', repetition in general can be read as a structural mirror of media and advertising, and its effect on cultural forms such as television has been to create a flow of repeatedly interrupted 
narratives punctuated by advertisements. The cycles, loops and phases of repetitive music mirror these media structures quite precisely. Fink contends, however, that drone minimalism can be viewed as a reflection of authoritarian and fundamentalist strains within the post-1960s counterculture, and, more generally, within modernity itself.

Part III concludes with a chapter by John Richardson and Susanna Välimäki, which sets theory into practice by exploring the audiovisual impulse in the music of Glass. Paying close attention to issues of temporality and synchronization in relation to theories on musical rhythm and questions of historical reference, the chapter highlights the pivotal role played by Glass's music in profiling the minimalist style in the audiovisual context by analysing its appearance in films such as The Hours, directed by Stephen Daldry, and Yes, directed by Sally Potter.

Analysis becomes a central theme in Part IV of this volume. Tristian Evans's chapter sets out to provide an initial overview of analytical methodologies in this area, giving special consideration to research undertaken by Naomi Cumming, Rebecca Leydon and others in the area of repetitive meanings. A highly nuanced hermeneutical model for analysing minimalist multimedia is then formulated, drawing on the Deleuzian notion of 'difference' and Michel Foucault's 'four similitudes'. Evans concludes his chapter by applying this model to a television advertisement by the telecommunications company Orange, featuring Reich's Music for Eighteen Musicians.

Pwyll ap Siôn addresses such analytical concerns in relation to reference, quotation and borrowing in minimalist and postminimalist music by identifying three distinct periods or phases. The first phase (during the 1960s) saw composers such as 
Reich and Terry Riley make use of found materials in their work, while the second phase (1970-80) used quotation in a very focused manner by presenting single rather than multiple sources. The period after the 1980s saw composers using reference and quotation in a variety of different ways, in keeping with the postminimalist aesthetic. Such approaches are considered in relation to a series of types, such as 'quotation as homage and critique', 'quotation as insertion' and 'quotation as integration or rupture'.

John Pymm's chapter considers the role of narrativity in minimalist music and outlines a methodology for analysing such works. His analysis of examples from Reich's early works seeks to show how narrative dimensions can still be uncovered in the context of a music purported to be non-linear, non-naturalistic and potentially non-narrated. The concluding chapter in this section by Marija Masnikosa proposes a theoretical model for minimalist and postminimalist music. She sets out two modalities for musical postminimalism: the first, which she calls 'postmodern minimalism', comprises works built wholly on minimalist processes upon which 'traces', codes or procedures from other non-minimalist musics are grafted. The second, called 'postminimalist postmodernism', incorporates a group of postmodernist works, which in addition to minimalist features also contain significant non-minimalist ones.

Part V presents three chapters where minimalism is seen as an influence or a catalyst for change in other areas, rather than playing a central role. David Dies provides a definition of 'spiritual minimalism' in his chapter. He argues that discussions of this repertoire have not directly addressed what is 'spiritual' about the music, offering a close reading of Arvo Pärt's Fratres in order to seek more precise musical characteristics for what listeners might identify as 'spiritual'. Dies proposes 
that this music induces a meditative attitude through the repetition of longer musical units and through conceptually simple structures that are in practice difficult to follow. Such compositional strategies allow listeners to experience this music as a form of transcendence, not unlike the Catholic rosary or Eastern Orthodox 'Jesus prayer.'

From Dies's chapter on sacred minimalism we move to Jonathan W. Bernard's study of minimalism and pop. He asks whether minimalism has, in fact, had a substantial impact upon the sensibilities of rock and pop composers and musicians, and what, indeed, would count as evidence of such an impact. Turning the question around, Bernard asks whether this encounter between minimalism and pop has affected our understanding of the term minimalist - as a classification of any kind - and if so, how? Drawing on a wide range of musical styles and genres (which also includes a web link to audio excerpts cited in his chapter), Bernard seeks to identify points of explicit contact between pop and minimalism in relation to elements such as harmony, texture, timbre, rhythm and duration.

The final chapter in Part V presents a fascinating case study in identifying regional and geographical characteristics of minimalism in a particular region, that of Serbia. Dragana Stojanović-Novičić traces minimalism's evolution in this area with particular reference to the 'Opus 4' group of composers, drawing parallels and differences with developments in other regions where relevant and appropriate. Similar case studies could have been presented in relation to a number of countries, of course, but such an undertaking would have been beyond the scope of this volume.

The final part of this book is reserved for a series of valuable personal insights from a number of important practitioners of minimalist music. All four musicians who 
have contributed to this section have many years of experience and understanding in performing or conducting this music: percussionist Russell Hartenberger with Steve Reich and Musicians, saxophonist John Harle with the Michael Nyman Band, pianist Sarah Cahill as both soloist and ensemble musician, and conductor and singer Paul Hillier as interpreter of Pärt's and Reich's music.

As this volume demonstrates, during the past 20 years or so musicology has recognized minimalist music as a serious academic subject, and has done so with more enthusiasm than have the general run of university-based composers. The present project derives from such music-historical concerns. In 2007, Pwyll ap Siôn and Tristian Evans organized the first International Conference on Minimalist Music at Bangor University in North Wales. Response from scholars was so overwhelming that they were forced to expand the conference timetable, and many enjoyed a wonderful minimalism fest on the banks of the Menai Straits, each astonished to meet so many other scholars sharing enthusiasms that many had been conditioned to consider a touch eccentric. Attendees to that conference formed the Society for Minimalist Music. David McIntire and Kyle Gann then directed the Society’s second conference in 2009 at the University of Missouri at Kansas City, and Maarten Beirens the third in 2011 at the University of Leuven. ${ }^{17}$ It is largely out of those conferences, and the activities of the Society for Minimalist Music, that the present volume has arisen.

\footnotetext{
${ }^{17}$ The fourth conference will be hosted jointly by UCLA and California State University at Long Beach, California, in October 2013.
} 
The editors are aware that, at this still-nascent stage of minimalist scholarship, it is difficult to bring this mass of music into focus and to do justice to every composer, technique and sub-movement with the proper weight and perspective to render the entire movement coherent. We have diversified our subject matter as much as practicable, but also given free rein to enthusiasms; realized that the Young/Riley/Reich/Glass nexus, plus Adams, remains of central interest, but also have been surprised at how much scholarship some of the supposed backwaters are now generating. The chapters collected here may provide a bumpy view of the movement with a few lacunae, but we are convinced that it represents some of the most exciting scholarship being done on minimalist music in the early twenty-first century.

Minimalism's origins may remain open to detailed debate, but its destination and ultimate significance continue to be open-ended. It has created, within the Western world, a new listening paradigm parallel to some of the traditions of Asia and Africa. It has vividly re-energized the concert hall and opera house. It has blurred the lines, once so preciously inviolate, between popular and classical music. Where it is ultimately heading, we can hardly even guess: we can only listen, read, and find out. 